International Journal of Child, Youth and Family Studies (2013) 4: 467-483

\title{
SELF-REPORTED SYMPTOMS AND PARENTS' EVALUATION OF BEHAVIOR PROBLEMS IN PRESCHOOLERS DISCLOSING SEXUAL ABUSE
}

\author{
Martine Hébert, Rachel Langevin, and Marie-Josée Bernier
}

\begin{abstract}
Child sexual abuse is a prevalent social problem known to have a deleterious impact on the mental health. While sexual abuse may affect preschool children, there is a lack of knowledge regarding its short-term correlates, namely regarding internalized symptomatology due to the few available self-report measures. This study aims to (a) contrast self-reported symptomatology in a group of sexually abused preschoolers and a group of non-abused children, and (b) provide preliminary data on the psychometric properties of the adapted French version of the PRESS. Results indicate that children in the sexual abuse group $(n=59)$ show higher levels of self-reported depressive symptoms than children in the comparison group $(n=66)$. Caregivers described sexually abused preschoolers as displaying more internalized and externalized behavior problems than their non-abused peers.
\end{abstract}

Keywords: child sexual abuse, preschoolers, depression, self-reports

Acknowledgements: This study was supported by a grant from the Social Sciences and Humanities Research Council of Canada (SSHRC) awarded to Martine Hébert. The study was also supported by infrastructure grants from the Chaire de recherche interuniversitaire Marie-Vincent sur les agressions sexuelles envers les enfants and the Fonds de recherche sur la société et la culture (FQRSC). The authors wish to thank the children, the parents, and the daycare workers who participated in this study. Special thanks are extended to the members of the Clinique de pédiatrie socio-juridique CHU SteJustine and of the Centre d'expertise Marie-Vincent.

Martine Hébert, Ph.D. (the corresponding author) is professor at the department of sexology, Université du Québec à Montréal, C.P. 8888, Succursale Centre-Ville, Montréal, Québec, Canada, H3C 3P8. Telephone: (514) 987-3000 \#5697, Fax: (514) 987-6787.

E-mail: hebert.m@uqam.ca.

Rachel Langevin is a Ph.D. candidate at the department of psychology, Université du Québec à Montréal, C.P. 8888, Succursale Centre-Ville, Montréal, Québec, Canada, H3C 3P8.

E-mail: langevin.rachel@gmail.com

Marie-Josée Bernier is a Ph.D. candidate at the department of psychology, Université du Québec à Montréal, C.P. 8888, Succursale Centre-Ville, Montréal, Québec, Canada, H3C 3P8. E-mail: marie-josee.bernier@live.ca 
International Journal of Child, Youth and Family Studies (2013) 4: 467-483

A host of empirical studies have documented the profiles of adult survivors, highlighting the devastating consequences associated with sexual abuse (SA) (Trickett, Noll, \& Putnam, 2011). In fact, recent reviews conclude that SA is a non-specific risk factor for a number of symptoms in adulthood including depression, suicidal ideations, anxiety, post-traumatic stress symptoms, as well as high-risk sexual behaviors (Maniglio, 2009). Despite the proliferation of studies examining long-term outcomes associated with SA, relatively few empirical studies have explored the short-term impact, and only a handful of empirical reports have specifically focused on outcomes in preschooler victims of SA. However, studies including young child victims of various and/or multiple forms of maltreatment, or investigating the impact of trauma exposure more broadly, have underscored the deleterious consequences of trauma in young children (e.g., Grasso, Ford, \& Briggs-Gowan, 2013).

Documenting the symptoms of preschoolers victimized by SA is relevant for several reasons. First, the prevalence of SA among preschoolers is quite high with almost $30 \%$ of child sexual abuse involving children aged 4 to 7 years (Putnam, 2003). Second, as shown by longitudinal studies of non-clinical populations, the preschool period is a crucial developmental period that may pave the way to long-standing and pervasive difficulties (Levi, Sogos, Mazzei, \& Paolesse, 2001). Third, a thorough evaluation of outcomes in children at this particular developmental phase may offer the necessary information required to underscore the need for intervention. Such interventions may in turn foster change in symptomatic behaviors given that behaviors are not yet crystallized in young children (Luby, Heffelfinger, Koenig-McNaught, Brown, \& Spitznagel, 2004).

Another argument for the relevance of exploring outcomes in sexually abused preschool children is that in maltreated populations, the impact of abuse may be associated with more serious long-term negative outcomes when the trauma occurs early. In one analysis, higher levels of depression and anxiety were identified for participants reporting abuse in the early years compared to those abused in later developmental periods (Kaplow \& Widom, 2007). Experiencing abuse at a younger age may indeed compromise essential developmental tasks, which are crucial from birth to school age (Calkins \& Hill, 2007). For instance, attachment security may be affected by early experiences of maltreatment, such as an incident of SA, especially if the abuser is a parental figure (Garber, Gallerani, \& Frankel, 2009).

Available studies highlight that the main outcomes associated with SA may be manifest in preschoolers. According to Trickett and Putnam (1998), the principal outcomes linked to an early onset of SA refer to somatic problems (such as enuresis), inappropriate sexualized behaviors, anxiety, social isolation behaviors, and possible developmental delays. In a recent study of 103 girls and 13 boys, victims of SA aged 3 to 6, Beaudoin, Hébert, and Bernier (2013) found that close to half (43\%) of sexually abused children were rated by the non-offending parent as reaching clinical levels of internalized behavior problems while 33\% achieved clinical levels of externalized behavior problems.

Few studies have contrasted sexually abused preschool children with non-abused children. However, in one such study, sexually abused preschoolers were found to display more inappropriate sexualized behaviors and behavior problems (Mian, Marton, \& LeBaron, 1996). In turn, maternal reports indicated that sexually abused children exhibited significantly more 
depression, anxiety, and social withdrawal than did their non-abused peers. Interestingly, Mian et al. (1996) reported that while sexually abused children scored higher than non-abused children on the internalized behavior problem scale, no significant difference was found on the externalized behavior problem scale. These results highlight the need to further explore the specificities of internalized symptoms in sexually abused children with a comparison group of non-abused children.

In one of the rare studies exploring possible age specificities in outcomes of sexually abused children, McCrae, Chapman, and Christ (2006) found that in their sample of 553 children (aged 3 to 14 years), 31\% reached clinical levels of internalization, while $46 \%$ reached clinical levels of externalization, based on parental reports. Of interest, the authors reported no differences between subgroups of different ages ( 3 to 7, 8 to 11, and 12 to 14 years old) regarding internalized and externalized symptomatology, suggesting that despite their young age, preschoolers may be as affected in the aftermaths of SA as older children. Self-reports of internalized symptoms (depressive and post-traumatic symptomatology) were unfortunately only available for older children ( $>7$ years), as the measures included were not appropriate for use with younger children.

In sum, studies documenting the symptomatology of preschooler victims of SA have reported significant internalized and externalized behavior problems. To date, studies have mostly relied on parental reports of behavioral problems. Hence, whether or not negative outcomes may be also highlighted in self-reports of young sexually abused children remains relatively unexplored. While parental ratings are essential in a detailed evaluation of young children's difficulties, self-reported measures of symptomatology, in combination with parents' perceptions, may offer additional relevant information regarding these difficulties (Weems, Taylor, Marks, \& Varela, 2010).

Regrettably, clinicians and researchers wanting to assess symptomatology directly from children face several challenges. Some believe that young children may not be developmentally capable of comprehending symptoms, namely those associated with internalized problems such as depression (Angold, Egger, \& Carter, 2007). Consequently, there is a paucity of developmentally appropriate self-report measures of depression for preschoolers (Levi et al., 2001) and evaluation of symptoms typically relies on reports from informants such as parents, teachers, or daycare workers (Luby, Belden, Sullivan, \& Spitznagel, 2007). Evaluation of internalized problems may pose particular challenges given such symptoms are not readily observable and not as disruptive to others compared to externalized behavior problems (Garber \& Carter, 2006; Weems et al., 2010). Informants may be more likely to focus on external and disturbing behaviors, possibly missing relevant information about the child's internal states and feelings. A study conducted by Weems and colleagues (2010) on discrepancies in parents' and children's evaluations of the children's anxiety sensitivity found that parents tend to underestimate their child's sensitivity to anxiety, while they tend to overestimate it in their adolescents. Lack of concordance between informants underscores the need to integrate selfreported measures of internalized behavior problems into the clinical assessment of children's symptoms.

In the specific case of child maltreatment, the issue is even more relevant as caregivers may overestimate or underestimate problems due to their own level of psychological distress 
following disclosure or the perceived impacts of their responses (Litrownik, Newton, \& Landsverk, 2005). A parent may attempt, unwillingly or not, to understate problems to avoid placement or overestimate problems to insure that intervention services will be available to their child. Studies have found that parental symptoms have been associated with a tendency for some parents to overestimate their child's behavior problems compared to reports from children or teachers (De Los Reyes \& Kazdin, 2005). Mothers of sexually abused children may be particularly vulnerable to psychological distress given the high prevalence of a past history of SA in this population (Kim, Trickett, \& Putnam, 2010). One recent study found that maternal history of SA predicted externalized behaviors even after controlling for family income and type and severity of sexual abuse experienced (Berthelot, Langevin, \& Hébert, 2012).

Relying on different sources of information is important in order to gather a more comprehensive view of children's profiles, as research clearly documents that cross-informant agreement is generally low. While this may be partially explained by the difficulty in observing internalized symptoms (Garber \& Carter, 2006), cross-informant discrepancies sometimes reflect real differences in children's behaviors across contexts and times (De Los Reyes, 2011). Thus, assessing symptoms in young child victims of SA by means of self-reports may offer salient information as to the consequences associated with SA. Few such measures are available, but the Preschool Symptom Self-Report or PRESS (Martini, Strayhorn, \& Puig-Antich, 1990) was designed to measure depressive symptoms specifically among preschool-aged children. The PRESS scale has been used in prior studies and has shown adequate reliability estimates with samples of preschool children (Dubowitz et al., 2001; Litrownik et al., 2005; Morrel, Dubowitz, Kerr, \& Black, 2003).

The present study aims to contrast self-reported symptomatology in a group of sexually abused preschoolers and a group of non-abused children. It is hypothesized that child victims of SA will report greater symptoms than non-abused children. In addition, we predicted that victims of more severe, chronic, and intrafamilial abuse would report greater symptoms than victims of less severe, less frequent, and extrafamilial abuse. A secondary aim of the study is to provide preliminary psychometric data on the adapted French version of the PRESS, namely by examining the internal consistency of the PRESS score and the discriminative power of individual items. In addition, cross-informant agreement will be explored by correlating selfreport scores with maternal reports of children's behavior problems.

\section{Method}

\section{Participants}

A sample of 59 sexually abused preschoolers (ages 4 to 6 years) and their non-offending caregivers were recruited at two intervention settings in Montréal, Québec, Canada offering specialized services to children disclosing sexual abuse: the Clinique de pédiatrie socio-juridique of the CHU Ste-Justine and the Centre d'expertise Marie-Vincent. A sample of 66 non-abused children recruited from daycare centers and kindergartens in the same city served as a comparison group. Sexually abused children were found to be comparable to non-abused children on all socio-demographic variables, except for family structure, maternal level of education, and family income (see Table 1). Only family structure was included as a co-variable in subsequent 
International Journal of Child, Youth and Family Studies (2013) 4: 467-483

analyses given the significant correlation between family structure, maternal level of education, and family income.

Table 1.

Socio-demographic Variables of the Sample and Group Differences

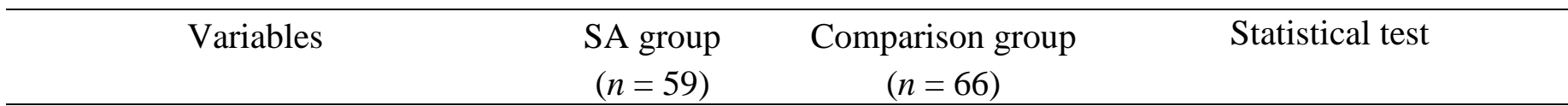

Average age of children (in

months)

$60.31(7.35)$

Gender of children

Girls

Boys

Family structure

Single-parent family

Intact or recomposed family

Maternal level of education

Elementary school

High school

College level

Undergraduate level

Graduate level

Annual family income

$<40000 \$$

$>40000 \$$

Duration of the abuse

One episode

Few episodes

Chronic

Severity of the abuse

Clothed touching

Unclothed touching

Penetration or attempted

Note: NA = not applicable.
$79.7 \%$

$20.3 \%$

$55.2 \%$

$45.8 \%$

$5.5 \%$

$52.7 \%$

$30.9 \%$

$10.9 \%$

$0 \%$

$64.3 \%$

$35.7 \%$

$36 \%$

$20 \%$

$44 \%$

$7 \%$

$25 \%$

$68 \%$
$59.11(6.01)$

$t_{(123)}=1.00 \mathrm{~ns}$

$\chi^{2}(1, N=125)=.82 n s$

$72.7 \%$

$27.3 \%$

$16.7 \%$

$83.3 \%$

$\chi^{2}(1, N=125)=20.21, p<.001$

$\chi^{2}(4, N=121)=45.85, p<.001$

$0.0 \%$

$7.5 \%$

$31.9 \%$

$43.9 \%$

$16.7 \%$

$16.7 \%$

83.3\%

$\chi^{2}(1, N=122)=29.01, p<.001$
NA

NA

NA 
International Journal of Child, Youth and Family Studies (2013) 4: 467-483

\section{Measures}

Preschool Symptom Self-Report. Children completed the 25-item (PRESS) pictorial scale designed by Martini and colleagues (1990). This self-report scale aims to assess depressive symptoms among preschool-aged children. Elaboration of the scale was guided by inspection of items loading on the depression factor of adult-rater scales including the Child Behavior Checklist and symptoms for depressive disorder on the DSM-III-R (Martini et al., 1990). The measure minimizes verbal ability by the use of drawings. Following two practice items, children are presented with two drawings simultaneously: one depicting a child without a problem behavior (coded as 0 ) and the other a child with a problem behavior or symptom (coded as 1). Scores are then summed to obtain a total score, with a higher score reflecting more endorsed symptoms. For the present study, the measure was adapted (adding new drawings) and translated for use with French-speaking children.

As in the original version of the PRESS, the position of the character illustrating either the presence or the absence of symptoms on the left or right side varied across items. Captions that describe each of the two illustrations are inscribed below each drawing and are read aloud as the child is invited to choose the one that is "most like you". Two sets of items were used (Boy/Girl version) according to the sex of the child (see sample items in Figure 1). Results reveal high internal consistency ( $\alpha=.82)$ for the adapted French version of the PRESS. All items show adequate item-total correlations except for two items (7 and 13) that presented lower but still positive item-total correlations (.10 and .18) (see Table 2). 
This girl is playing and not having fun
This boy thinks that he is not good looking
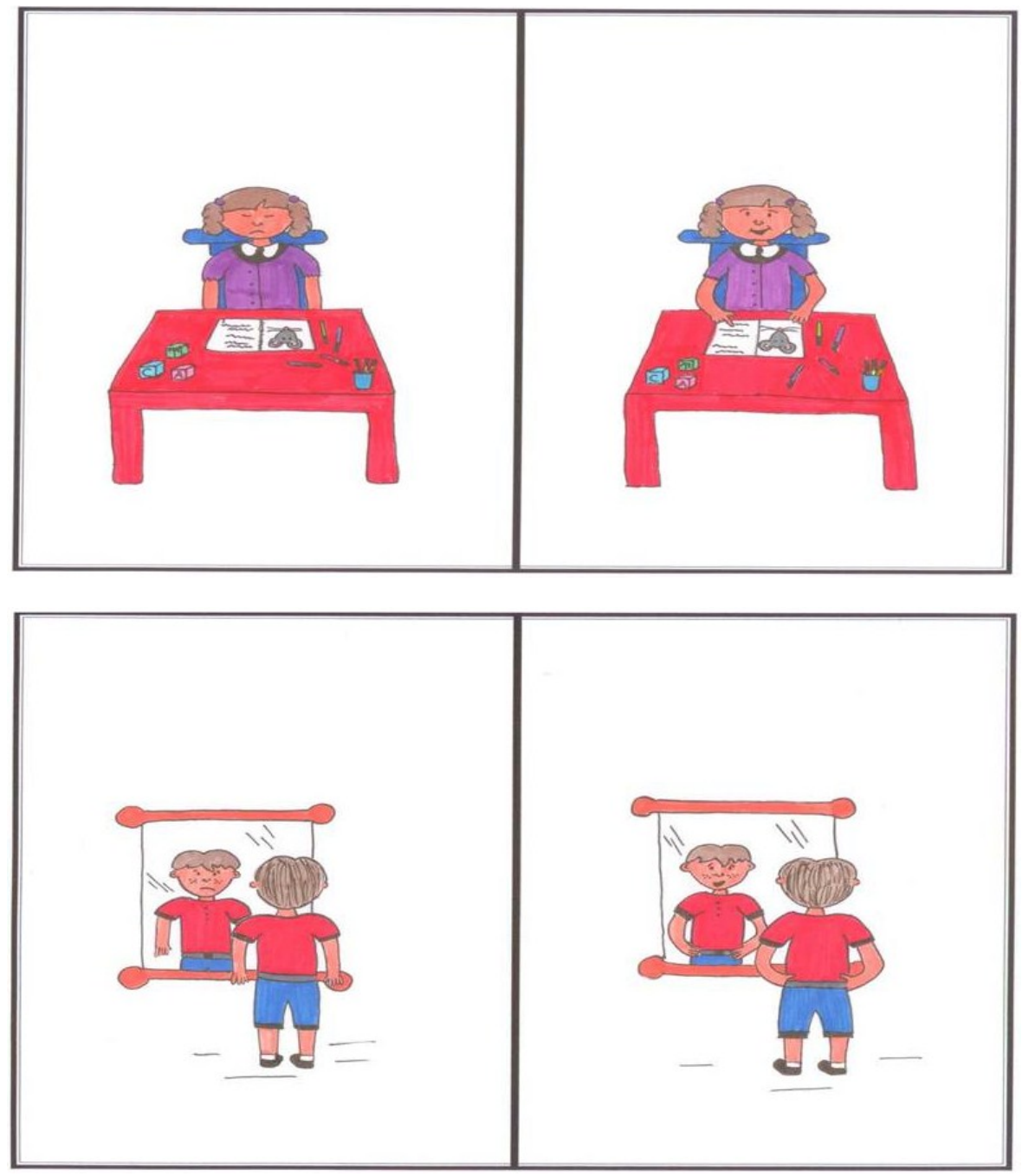

Figure 1. Example items for anhedonia and self-esteem.

Table 2. Item-total Correlations of the Adapted Version of the PRESS

\begin{tabular}{clc}
\hline Item number & Item description $^{\mathrm{a}}$ & Corrected item-total correlation \\
\hline 1 & Depressed mood & .46 \\
\hline 2 & Frustration tolerance & .27 \\
\hline 3 & Feeling unloved & .27 \\
\hline 4 & Self-image & .45 \\
\hline
\end{tabular}

This girl is playing and having fun
This boy thinks that he is good looking 
International Journal of Child, Youth and Family Studies (2013) 4: 467-483

\begin{tabular}{|c|c|c|}
\hline 5 & Self-image & .33 \\
\hline 6 & Worrying & .44 \\
\hline 7 & Anhedonia & .10 \\
\hline 8 & Anhedonia & .23 \\
\hline 9 & Irritability and anger & .35 \\
\hline 10 & Fatigue & .44 \\
\hline 11 & Insomnia & .32 \\
\hline 12 & Socialization & .31 \\
\hline 13 & Appetite decrease & .18 \\
\hline 14 & Somatization & .33 \\
\hline 15 & Fearful & .33 \\
\hline 16 & Sadness & .25 \\
\hline 17 & Irritability & .26 \\
\hline 18 & Social isolation & .44 \\
\hline 19 & Separation anxiety & .29 \\
\hline 20 & Socialization & .44 \\
\hline 21 & Teasing & .30 \\
\hline 22 & Fearful & .53 \\
\hline 23 & Psychomotor deficit & .62 \\
\hline 24 & Decreased concentration & .52 \\
\hline 25 & Disobedience & .36 \\
\hline \multicolumn{2}{|c|}{ Internal consistency of the total score } & $\alpha=.82$ \\
\hline
\end{tabular}

Note: Derived from Martini, Strayhorn, and Puig-Antich (1990). 
International Journal of Child, Youth and Family Studies (2013) 4: 467-483

Child Behavior Checklist. The non-offending parent completed the preschool version of the Child Behavior Checklist or CBCL (Achenbach \& Rescorla, 2000). The parent was invited to answer each question on a three-point Likert scale indicating the frequency of the behavior manifested by the child $(0=$ Not true; 1 = Somewhat or sometimes true; $2=$ Very true or often true). Items associated with dimensions of internalizing (anxiety, depression, somatization, etc.) behavior problems and externalizing (e.g., aggressivity) were considered. $T$ scores are calculated, with a higher score indicative of higher levels of behavior problems. The CBCL is used extensively in clinical research. Internal consistency of scores for the internalizing $(\alpha=0.89)$ and externalizing scores $(\alpha=0.92)$ are adequate and numerous studies support the validity of the scale (Achenbach \& Rescorla, 2000; Keenan \& Wakschlag, 2000).

\section{Procedure}

For the sexual abuse group, parents completed questionnaires with the assistance of a research assistant in the intervention setting while parents in the comparison group completed questionnaires at home. Written informed consent was obtained from parents after explaining the study's aims and procedures to them, while verbal consent was solicited from children. The Human Research Review Committees of the Université du Québec à Montréal (UQAM) and the Ethics Committee of the CHU Sainte-Justine Mother and Child University Hospital Center approved this study.

\section{Results}

\section{Group Differences in Self-reported Symptoms}

A univariate analysis of covariance (ANCOVA) was performed to determine if there was a difference between the SA victims group and the comparison group on self-reported depressive symptomatology, while controlling for family structure. Results show that the mean score of the PRESS is higher in the victims group than in the comparison group (SA Group: adjusted $M=$ 4.01; Comparison Group: adjusted $\left.M=2.14 ; F_{(1,121)}=7.93, p<0.01\right)$.

Analysis of endorsement for each item revealed that nine items of the PRESS scale discriminate between sexually abused and non-abused children. The item highlighting the highest difference in endorsement refers to somatization (item 14). Other items discriminating between groups are related to depressed mood (item 1), feeling unloved (item 3), self-image (item 4), worrying (item 6), fatigue (item 10), sadness (item 16), socialization (item 20), and psychomotor deficit (item 23) (see Table 3 for details).

To evaluate possible differences according to type of abuse experienced (intra- or extrafamilial abuse), children in the SA group were divided into two groups according to the nature of the relationship between the child and its abuser. Results indicate that victims of intra-familial abuse obtained a significantly higher mean score for self-reported depressive symptoms $(M=$ $4.95 S D=4.21)$ than child victims of a non-family related or unrelated abuser $(M=2.07 S D=$ $\left.2.40 ; t_{(55)}=2.42, p<0.05\right)$. Children experiencing penetration or attempted penetration achieved a higher mean score on the PRESS scale $(M=5.05 S D=3.98)$ than child victims of clothed or unclothed touching $\left(M=2.78 S D=3.78 ; t_{(54)}=2.03, p<0.05\right)$. Analysis based on the length of the abuse failed to identify a significant difference as children reporting more than one episode of 
International Journal of Child, Youth and Family Studies (2013) 4: 467-483

SA $(M=3.86 S D=4.13)$ did not differ from children reporting a single episode of SA $(M=4.69$ $\left.S D=4.22 ; t_{(43)}=0.64, n s\right)$.

\section{Table 3. Items Discriminating Between Abused and Non-abused Children}

Items (this boy/girl...)
$\%$

SA group Comparison group

1 Is sad and is crying most of

$23.7 \%$

$7.6 \% *$

the time

3 Thinks parents do not love her/him

$10.2 \%$

$1.5 \% *$

4 Thinks that she/he is not good looking

$$
15.3 \%
$$

$4.5 \% *$

6 Does not want to leave

$23.7 \%$

$9.1 \% *$ her/his father and play outside, she/he thinks he will go away

10 Is tired and does not want to $22.0 \%$

$9.1 \% *$ play

14 Feels sick and doesn't want to go out and play

$25.4 \%$

$3.0 \% * * *$

16 Is feeling bad about

$10.2 \%$ $0.0 \% * *$ her/himself, is sad

20 Other boys and girls do not like this child

23 Feels does not have enough energy to keep up with friends

Note. ${ }^{*} p<.05 .{ }^{* *} p<0.01 .{ }^{* * *} p<.001$ 
International Journal of Child, Youth and Family Studies (2013) 4: 467-483

\section{Group Differences in Caregivers' Ratings of Children's Behavior Problems}

ANCOVAs controlling for family structure revealed that caregivers of sexually abused children report both higher internalized $\left(F_{(1,119)}=51.68, p<0.001\right)$ and externalized behavior problems levels $\left(F_{(1,119)}=31.07, p<0.001\right)$.

Analyses were also performed to ascertain whether the proportion of children reaching clinical levels of behavior problems ( $T$ score $>70$ ) was different across groups. Results showed a significant difference as $42.9 \%$ of sexually abused children reached clinical levels of internalization, while only $1.5 \%$ of non-abused children did so $\left(\chi^{2}(1, N=122)=31.78, p<\right.$ $.001)$. In the SA group, 30.4\% of children displayed clinical levels of externalization, while only $1.5 \%$ of children in the comparison group reached clinical levels $\left(\chi^{2}(1, N=122)=20.04, p<\right.$ $.001)$.

\section{Correlations Between Self-reports and Caregivers’ Ratings}

Results indicate a significant correlation between PRESS total score and parental ratings of child's externalized behavior problems $(r=.22, p<0.05)$. A marginally significant correlation was found with internalized behavior problems $(r=.15, p<0.10)$.

\section{Discussion}

The main objective of this study was to document self-reported symptomatology of preschooler victims of SA by contrasting them with a group of non-abused children. In line with our hypothesis, results indicate that sexually abused children self-report higher levels of depressive symptoms than their non-abused counterparts. Specific items appear to be salient to discriminate between the SA and the comparison group. The item presenting the greatest discriminant power concerns somatization, which is coherent with Trickett and Putnam's (1998) observation that somatization is an outcome frequently associated with SA in preschoolers. Preschool-aged children may not be as developmentally capable as older children in expressing the complex feelings associated with SA and/or using efficient coping strategies to overcome the trauma experienced (Yancey \& Hansen, 2010), resulting in somatization of the distress. A recent study by Kugler, Bloom, Kaercher, Truax, and Storch (2012), with a sample of older children (8 to 17 years old) in residential care, found that while other forms of maltreatment (physical abuse, emotional abuse, neglect, or witnessing domestic violence) were not associated with higher selfreported symptoms, somatic symptoms discriminated between child victims of sexual abuse and those who had not been sexually abused. These somatic symptoms may affect SA victims even later in adulthood as Zink, Klesges, Stevens, and Decker (2009) found, namely that experiencing SA at an earlier age was associated with greater somatic symptoms.

Another important item that was differentially answered according to groups related to sadness. Sadness appears to be a central symptom in depression, even for preschool children (Luby, Belden, Pautsch, Si, \& Spitznagel, 2009). However, Luby and colleagues (2009) reported that in their study, contrary to their expectations, sadness was found to be a relatively unspecific symptom of depression compared with anxiety and disruptive disorders in young children. 
Close to one out of five children reporting SA endorsed the item regarding not being liked by their peers. Greater endorsement of this item by children in the SA group may reflect an impairment in children's social functioning. Impairment is a central diagnostic criterion in psychopathology, including depression. Stigmatization and feelings of shame often experienced by child victims of SA (Feiring \& Cleland, 2007) may introduce a sense of being different from their peers, and as such young children may be susceptible to the development of feelings of social isolation (Finkelhor \& Browne, 1985). In addition, SA may generate a sense of betrayal likely to affect interpersonal trust in others, a critical element in the development of social relationships (Blanchard-Dallaire \& Hébert, in press). Finally, emotion dysregulation in maltreated children is associated with disruptive behaviors, which in turn may be linked to peer rejection (Kim \& Cicchetti, 2010).

Our results revealed that child victims of intra-familial SA report higher levels of depressive symptomatology than victims of extra-familial SA, results in concordance with prior studies with samples of older children or adults (Hébert, Tremblay, Parent, Daignault, \& Piché, 2006). Victims of abuse involving a close family member abuser may experience a higher sense of helplessness, which is known to be linked to depressive behavior (Garber \& Carter, 2006). As proposed by Finkelhor and Browne (1985) in their conceptualization of the traumatic impact of SA, powerlessness or the sense of losing power over their own selves can also lead to symptoms of depression and anxiety. Both helplessness and feelings of powerlessness may be more salient in victims of abuse perpetrated by close family members due to the potential aftermath of disclosing the abuse and the possible fear of not being believed.

Self-reported symptoms were also endorsed more frequently by preschool children experiencing penetration or attempted penetration which is consistent with past studies with older children highlighting that severity of abuse is related to clinical profiles at intake (Yancey, Naufel, \& Hansen, 2013). Our data failed to identify significant difference between duration of SA and self-reports of symptoms. Obtaining reliable information regarding the duration of the abuse experienced may represent an important challenge, especially when reports of preschoolers are concerned, given the sense of time is under development. It is also possible that the full details of the duration of the abuse experienced are not provided at initial intake but rather gradually given over the course of treatment, once rapport is established.

Our study provides initial data on psychometric properties of the French version of the PRESS. The total score showed a high level of internal consistency with children as young as 4 to 6 years, thus suggesting that responses are not random but consistent across items. Our data also offers some support for validity of the French version of the PRESS as scores of self-reported depressive symptomatology were found to be correlated with caregivers' reports of externalized and internalized behavior problems, while this last correlation was marginally significant.

Prior studies exploring cross-informant agreement with the original version of the PRESS have yielded inconsistent results. In Martini et al.’s (1990) study, self-reports did not correlate with either the parent or teacher version of the PRESS. In Litrownick et al.'s (2005) study, crossinformant agreement was found between the PRESS score and externalized behavior problems as rated by primary caregivers only for younger children (aged 3) in the foster care sample. However, caregivers' reports of behavior problems were not related to self-reports of depressive 
International Journal of Child, Youth and Family Studies (2013) 4: 467-483

symptomatology in children ages 4 to 7 . Morrel et al. (2003) found that self-reports based on the PRESS were correlated with parental reports of children's internalizing and externalizing problems, but only for mothers reporting a history of physical and/or sexual victimization. Clearly, additional studies are needed to explore the complex interplay between age of the child, informant and possible characteristics of informants (for instance, victimization history or psychological distress), and level of agreement.

The study presents certain limitations. Sample size, while comparable to other published studies, is small and did not allow sufficient power to conduct gender-based analyses. Another limitation of this study is its transversal design, which prevents the drawing of causal conclusions regarding the studied variables. Further analysis of the psychometric properties of the French version of the PRESS, including exploring the stability of scores and concomitant validity with other self-report measures, as well as with clinician-based ratings of symptomatology, are needed. In addition, future studies should evaluate the potential value of the PRESS score as an index of change during the course of treatment. While participants were recruited from two of the main centers offering specialized services to preschoolers disclosing SA in Montréal, our sample is nevertheless based on families that sought services and/or were identified and referred to services by CPS agencies or police authorities. Therefore, our results may not generalize to the population of sexually abused children that includes a number of cases that are not disclosed.

Notwithstanding these limits, this study has a number of strengths. The inclusion of a comparison group allows us to draw stronger conclusions regarding the profiles of preschooler victims of SA, a population that is clearly understudied. The reliance on a self-report measure for this specific clientele is also innovative and our results provide preliminary evidence regarding the usefulness of the French version of the PRESS scale to discriminate between sexually abused children and non-abused children and, within the SA group, those reporting severe and intrafamilial abuse. Such documentation may sustain future studies exploring internalized symptoms with this population of young children. Soliciting data from multiple informants with children who are victims of SA will not only contribute to a more comprehensive picture of symptomatology but also highlight discrepancies between parent and child reports that may predict subsequent poorer child outcomes (Goodman, De Los Reyes, \& Bradshaw, 2010). 
International Journal of Child, Youth and Family Studies (2013) 4: 467-483

\section{References}

Achenbach, T., \& Rescorla, L. (2000). Manual for ASEBA preschool forms \& profiles: An integrated system of multi-informant assessment. Burlington, VT: University of Vermont, Research Center for Children, Youth, \& Families.

Angold, A., Egger, H. L., \& Carter, A. (2007). Measurement of psychopathology in children under age of six. In W. E. Narrow, M. B. First, P. J. Sirovatka, \& D. A. Regier (Eds.), Age and gender considerations in psychiatric diagnosis (pp. 177-189). Arlington, VA: American Psychiatric Association.

Beaudoin, G., Hébert, M., \& Bernier, A. (2013). Contribution of attachment security to the prediction of internalizing and externalizing behavior problems in preschooler victims of sexual abuse. European Review of Applied Psychology, 63(3), 147-157. doi: 10.1016/j.erap.2012.12.001

Berthelot, N., Langevin, R., \& Hébert, M. (2012). L’association entre la victimisation sexuelle dans l'enfance de la mère et les troubles de comportement chez l'enfant victime d'agression sexuelle [Association between maternal childhood sexual victimization and behavior problems in sexually abused chidren]. Journal international de victimologie/The International Journal of Victimology, 10(1), 8-20.

Blanchard-Dallaire, C., \& Hébert, M. (in press). Social relationships in sexually abused children: Self-reports and teachers' evaluation. Journal of Child Sexual Abuse.

Calkins, S. D., \& Hill, A. L. (2007). Caregiver influences on emerging emotion regulation: Biological and environmental transactions in early development. In J. J. Gross (Ed.), Handbook of emotion regulation (pp. 229-248). New York: The Guilford Press.

De Los Reyes, A. (2011). Introduction to the special section: More than measurement error: Discovering meaning behind informant discrepancies in clinical assessments of children and adolescents. Journal of Clinical and Adolescent Psychology, 40(1), 1-9. doi: 10.1080/15374416.2011.533405

De Los Reyes, A., \& Kazdin, A. E. (2005). Informant discrepancies in the assessment of childhood psychopathology: A critical review, theoretical framework, and recommendations for further study. Psychological Bulletin, 131(4), 483-509. doi: 10.1037/0033-2909.131.4.483

Dubowitz, H., Black, M. M., Cox, C. E., Kerr, M. A., Litrownik, A. J., Radhakrishna, A., et al. (2001). Father involvement and children's functioning at age 6 years: A multisite study. Child Maltreatment, 6(4), 300-309. doi: 10.1177/1077559501006004003

Feiring, C., \& Cleland, C. (2007). Child sexual abuse and abuse-specific attributions of blame over 6 years following disclosure. Child Abuse \& Neglect, 31(11-12), 1169-1186. doi: 10.1016/j.chilabu.2007.03.020 
International Journal of Child, Youth and Family Studies (2013) 4: 467-483

Finkelhor, D., \& Browne, A. (1985). The traumatic impact of child sexual abuse: A conceptualization. American Journal of Orthopsychiatry, 55(4), 530-541. doi: 10.1111/j.1939-0025.1985.tb02703.x

Garber, J., \& Carter, J. S. (2006). Major depression. In M. Hersen, J. C. Thomas, \& R. T. Ammerman (Eds.), Comprehensive handbook of personality and psychopathology: Child psychopathology (pp. 165-216). Hoboken, NJ: John Wiley \& Sons, Inc.

Garber, J., Gallerani, C. M., \& Frankel, S. A. (2009). Depression in children. In I. Gotlib \& C. L. Hammen (Eds.), Handbook of depression (pp. 405-443). New York: Guilford Press.

Goodman, K. L., De Los Reyes, A., \& Bradshaw, C. P. (2010). Understanding and using informants' reporting discrepancy of youth victimization: A conceptual model and recommendations for research. Clinical Child \& Family Psychology Review, 13(4), 366383. doi: 10.1007/s10567-010-0076-X

Grasso, D. J., Ford, J. D., \& Briggs-Gowan, M. J. (2013). Early life trauma exposure and stress sensitivity in young children. Journal of Pediatric Psychology, 38(1), 94-103. doi : 10.1093/jpepsy/jss101

Hébert, M., Tremblay, C., Parent, N., Daignault V. I., \& Piché, C. (2006). Correlates of behavioral outcomes in sexually abused children. Journal of Family Violence, 21(5), 287299. doi: 10.1007/s10896-006-9026-2

Kaplow, J. B., \& Widom, C. S. (2007). Age of onset of child maltreatment predicts long-term mental health outcomes. Journal of Abnormal Psychology, 116(1), 176-187. doi: 10.1037/0021-843x.116.1.176

Keenan, K., \& Wakschlag, L. S. (2000). More than the terrible twos: The nature and severity of behavior problems in clinic-referred preschool children. Journal of Abnormal Child Psychology, 28(1), 33-46. doi: 10.1023/a:1005118000977

Kim, J., \& Cicchetti, D. (2010). Longitudinal pathways linking child maltreatment, emotion regulation, peer relations, and psychopathology. Journal of Child Psychology and Psychiatry, 51(6), 706-716. doi: 10.1111/j.1469-7610.2009.02202.x

Kim, K., Trickett, P. K., \& Putnam, F. W. (2010). Childhood experiences of sexual abuse and later parenting practices among non-offending mothers of sexually abused and comparison girls. Child Abuse \& Neglect, 34(8), 610-622. doi: 10.1016/j.chiabu.2010.01.007

Kugler, B. B., Bloom, M., Kaercher, L. B., Truax, T. V., \& Storch, E. A. (2012). Somatic symptoms in traumatized children and adolescents. Child Psychiatry and Human Development, 43(5), 661-673. doi: 10.1007/s10578-012-0289-y

Levi, G., Sogos, C., Mazzei, E., \& Paolesse, C. (2001). Depressive disorder in preschool children: Patterns of affective organization. Child Psychiatry and Human Development, 32(1), 55-69. 
International Journal of Child, Youth and Family Studies (2013) 4: 467-483

Litrownik, A. J., Newton, R. R., \& Landsverk, J. A. (2005). Assessment of depressive symptomatology in young maltreated children. Journal of Human Behavior in the Social Environment, 11(3/4), 135-156. doi: 10.1300/J137v11n03_07

Luby, J. L., Belden, A. C., Pautsch, J., Si, X., \& Spitznagel, E. (2009). The clinical significance of preschool depression: Impairment in functioning and clinical markers of the disorder. Journal of Affective Disorders, 112, 111-119. doi:10.1016/j.jad.2008.03.026

Luby, J. L., Belden, A., Sullivan, J., \& Spitznagel, E. (2007). Preschoolers’ contribution to their diagnosis of depression and anxiety: Uses and limitations of young child self-report of symptoms. Child Psychiatry \& Human Development, 38(4), 321-338. doi: 10.1007/s10578-007-0063-8

Luby, J. L., Heffelfinger, A., Koenig-McNaught, A. L., Brown, K., \& Spitznagel, E. (2004). The preschool feelings checklist: A brief and sensitive screening measure for depression in young children. Journal of the American Academy of Child \& Adolescent Psychiatry, 43(6), 708-717. doi: 10.1097/01.chi.0000121066.29744.08

Maniglio, R. (2009). The impact of child sexual abuse on health: A systematic review of reviews. Clinical Psychology Review, 29(7), 647-657. doi: 10.1016/j.cpr.2009.08.003

Martini, D. R., Strayhorn, J. M., \& Puig-Antich, J. (1990). A symptom self-report measure for preschool children. Journal of the American Academy of Child \& Adolescent Psychiatry, 29(4), 594-600. doi: 10.1097/00004583-199007000-00013

McCrae, J. S., Chapman, M. V., \& Christ, S. L. (2006). Profile of children investigated for sexual abuse: Association with psychopathology symptoms and services. American Journal of Orthopsychiatry, 76(4), 468-481. doi: 10.1037/0002-9432.76.4.468

Mian, M., Marton, P., \& LeBaron, D. (1996). The effects of sexual abuse on 3- to 5-year-old girls. Child Abuse \& Neglect, 20(8), 731-745. doi: 10.1016/0145-2134(96)00061-0

Morrel, T. M., Dubowitz, H., Kerr, M. A., \& Black, M. M. (2003). The effect of maternal victimization on children: A cross-informant study. Journal of Family Violence, 18(1), 29-41. doi: 10.1023/A:1021401414414

Putnam, F. W. (2003). Ten-year research update review: Child sexual abuse. Journal of the American Academy of Child \& Adolescent Psychiatry, 42(3), 269-278. doi: 10.1097/00004583-200303000-00006

Trickett, P. K., Noll, J. G., \& Putnam, F. W. (2011). The impact of sexual abuse on female development: Lessons from a multigenerational, longitudinal research study. Development and Psychopathology, 23(2), 453-476. doi: 10.1017/s0954579411000174

Trickett, P., \& Putnam, F. W. (1998). Developmental consequences of child sexual abuse. In P. K. Trickett \& C. J. Schellenbach (Eds.), Violence against children in the family and the community (pp. 39-56). Washington, DC: American Psychological Association. 
International Journal of Child, Youth and Family Studies (2013) 4: 467-483

Weems, C. F., Taylor, L. K., Marks, A. B., \& Varela. R. E. (2010). Anxiety sensitivity in childhood and adolescence: Parent reports and factors that influence associations with child reports. Cognitive Therapy Research, 34(4), 303-315. doi: 10.1007/s10608-0089222-X

Yancey, C. T., \& Hansen, D. J. (2010). Relationship of personal, familial, and abuse-specific factors with outcome following childhood sexual abuse. Aggression and Violent Behavior, 15(6), 410-421. doi: 10.1016/j.avb.2010.07.003

Yancey, C. T., Naufel, K. Z., \& Hansen, D. J. (2013). The relationship of personal, family, and abuse-specific factors to children's clinical presentation following child sexual abuse. Journal of Family Violence, 28, 31-42. doi:10.1007/s10896-012-9485-6

Zink, T., Klesges, L., Stevens, S., \& Decker, P. (2009). The development of a sexual abuse severity score: Characteristics of childhood sexual abuse associated with trauma symptomatology, somatization, and alcohol abuse. Journal of Interpersonal Violence, 24(3), 537-546. doi: 10.1177/0886260508317198 